\title{
Virtual Faculty Strategies for Supporting Motivation of Online Doctoral Students
}

Crissie M. Jameson, $\mathrm{PhD}$

Walden University, Minneapolis, Minnesota, United States

Kelly M. Torres, PhD

The Chicago School of Professional Psychology, Chicago, Illinois, United States

Shereeza F. Mohammed, $\mathrm{PhD}$

Walden University, Minneapolis, Minnesota, United States

Contact: crissie.jameson@mail.waldenu.edu

\section{Abstract}

Our study focused on online faculty members and their perceptions of the strategies and activities they use to promote progress for and motivation in their online graduate students, particularly at the dissertation/doctoral study phase of the program. Results show high-achieving faculty members vary their strategies according to each students' needs. High-achieving faculty members reach out to students often, offer encouragement throughout the process, and establish realistic goals.

Keywords: virtual faculty, online students, doctoral students, motivation

Date Submitted January 8, 2021 | Date Published: November 3, 2021

\section{Recommended Citation}

Jameson, C. M., Torres, K., \& Mohammed, S. (2021). Virtual faculty strategies for supporting motivation of online doctoral students. Journal of Educational Research and Practice, 11, 297-307.

https://doi.org/10.5590/JERAP.2021.11.1.21

\section{Introduction}

Starting in March 2020, the incidence of COVID-19 in the United States resulted in the immediate shift to online learning by institutions of higher education, many of which were not offering much in terms of online learning before this period. Such a change impacted a variety of fields at all levels of learning, from undergraduates to graduate and doctoral programs. Several researchers have discussed how different institutions and disciplines have innovated to address the challenges of their fields, including those involving the more hands-on approach of training not typically conducted online (Bohan \& Perrotta, 2020; Saiyad et al., 2020; Taylor et al., 2020). In fact, Taylor et al. (2020) discussed these changes in terms of needing to learn and communicate in new ways and emphasized how quickly the response was needed to innovate new teaching and learning strategies. This involved adaptation to, among other challenges, building competency in faculty to "transfer all the student's support and mentorship activities from fully face to face to a fully online platform" (p. 76). 
Because online doctoral mentoring can encompass many components, including advising, modeling, encouraging, promoting, and guiding students through the research process (Kumar \& Coe, 2017), faculty members need to use mentorship strategies effectively to enhance students' levels of motivation toward degree completion. However, online faculty members may experience difficulties in providing mentorship in online learning contexts (Kumar \& Coe, 2017) since they most likely received mentoring in their graduate studies through face-to-face interactions. As a result, faculty members may need to adjust their mentoring strategies when working with online versus traditional, on-ground learners. Further, institutions may need to provide professional development opportunities that help faculty members acquire effective mentoring skills. For example, Kumar and Johnson (2017) proposed that:

The use of multiple technologies to mentor research and communicate with students; negotiation of expectations for drafts and updates; implementation of clear structures for online mentoring and dissertation procedures; and provision of timely feedback, psychosocial support, and exemplars of quality writing in the online environment can create a dissertation experience to facilitate mentees' growth, autonomy, and successful dissertation completion. (pp. 219-220)

Since faculty members may not have been explicitly taught how to provide effective virtual mentoring approaches, institutions need to consider how best to support faculty members in their development of these skills. One option could be for institutions to provide workshops or symposia to faculty members who are new or in the process of transitioning to chair online doctoral students. Mahsood et al. (2018) found that various professional development opportunities were perceived positively by faculty members in enhancing their professional practices and teaching skills. Steinert et al. (2016) further discovered that faculty development initiatives were not only perceived positively by faculty members but also resulted in their increased levels of effective educational practices, enthusiasm, and self-confidence. Moreover, due to the complexities associated with mentoring, faculty members may need to reflect on what strategies may be most effective in connecting with their online mentees. Reflective practitioners can adopt "a reflective stance toward their practice as a means of ongoing professional development" (Kayapinar, 2016, p. 1672). This, in turn, may result in faculty members using reflective practices to continually improve their mentorship approaches. By restructuring their perceptions of the mentoring process, faculty members may be able to support their mentees better as they progress through their dissertation research, and they may be able to assist students in acquiring higher levels of self-confidence in their ability to conduct future research. Through this type of mentorship approach, students may be more motivated to continually make dissertation progress and successfully complete their doctoral studies.

Our present research was a follow-up study to one conducted in spring, 2018 that focused on students and their perceptions of how online faculty members supported and motivated their progress in the dissertation/doctoral study phase of their online graduate program. Conversely, this study focused on faculty members and their perceptions of the strategies and activities they use to promote progress for and motivation in their online graduate students, particularly at the dissertation/doctoral study phase of the program.

\section{Supporting Motivation}

Motivation can be either extrinsic (externally focused) or intrinsic (internally focused). Ryan and Deci considered intrinsic motivation to be a more powerful motivator for keeping students engaged and making progress on their academic pursuits (Ryan \& Deci, 2000). Motivation can change (between intrinsic and extrinsic) over time; however, research continues to demonstrate that intrinsic motivation is a powerful factor for keeping a doctoral student from dropping out or not making progress (Templeton, 2016; Thunborg et al., 2013). 
When people are intrinsically motivated, they enjoy engaging in learning activities. These behaviors then have an internal perceived locus of causality-coming from internal sources rather than external sources (deCharms, 1968). This motivation fuels one's interest and autonomy, which is central to promote a learner's progress and development (Deci \& Ryan, 1985; Flavell, 1999). Deci and Ryan's (1985) Self-Determination Theory was used as the framework for our study to examine the research questions listed. The constructs of autonomy (choice), competence (ability), and relatedness (connectedness) were used to create the survey items used in data collection.

The purpose of our study was to investigate virtual faculty strategies to support online doctoral students' motivation to continue in the program and, ultimately, graduate.

\section{Method}

\section{Design}

The methodology for our study was an exploratory case study (Yin, 2003), which was appropriate as it examines the perceptions and rich experiences of those in the case (Yin, 2014). For our study, the case is virtual faculty members who serve as chairs on dissertation/doctoral committees for online doctoral students at two different online universities. The two different localities of participants provided a single case for collecting data, but each university is considered its own subcase as they are slightly dissimilar and from a different participant pool of faculty members. Additionally, we used a combination qualitative questionnaire and quantitative survey to collect the data (see the Appendix). We used both open-ended (qualitative) items that required participants to write out their responses and Likert-scale items (quantitative) that were analyzed descriptively. The data from each part of the instrument were triangulated to produce the findings to answer the two research questions.

Research Question 1: How do virtual faculty members support motivation (i.e., autonomy, competence, and relationships) of online doctoral students?

Research Question 2: How do virtual faculty members act as mentors to online doctoral students?

\section{Institution A}

University A is a large, private, for-profit, online university offering degrees ranging from bachelor's to doctoral degrees. Graduate students comprise approximately $75 \%$ of the student population. Many of the university's students are working professionals who are balancing professional, personal, and academic demands. Faculty members are trained practitioners in their fields and are experienced online educators, but they are also trained by the university on best practices for online teaching as new and continuing faculty members. The university faculty members possess academic and industry credentials that allow for the inclusion of practical examples into their program curriculum.

\section{Institution B}

University B is a not-for-profit institution that consists of eight campuses, which include seven on-ground campuses and an online campus. The online campus contains the largest student enrollment at the university. Approximately $79 \%$ of the student population are graduate students. Many university students are working professionals who are balancing professional, personal, and academic demands. Similarly, the faculty members at Institution B are trained practitioners who possess professional experiences outside of academia that they incorporate into their courses. Online faculty members who teach in doctoral programs at the institution are required to complete trainings focused on best practices in online teaching and mentoring dissertation students. 
Both institutions in which data were collected for our study have supported online doctoral students for more than 40 years, so these faculty respondents were likely familiar with the particular needs of online doctoral students.

\section{Participants}

Institution A. The sample came from the participant pool of a large, American-based, online university population consisting of students and faculty members. Faculty members who opted in to become participants received a login and password and were then able to participate in research studies posted to the site. The online survey was accessed via a link on the website to faculty members currently in the participant pool. Monthly emails were sent to all participant pool enrollees as a way to encourage participants to take part in the research being conducted. The participant pool site was open to any U.S. adult, but it was only advertised on the large, for-profit university site pages to increase the chance that the participants were faculty members of that university. The survey link was also featured in various institutional faculty newsletters.

Institution B. The participants in our study included faculty members from the institution's Online Campus. Participants represented faculty members from six different online doctoral programs of study. For our study, online faculty members were contacted to participate in the study and were provided an electronic survey link. This institution does not offer a participant pool for research.

\section{Data Collection}

The data collection began just before the pandemic in the United States (approximately March, 2020 in most states) but continued through the first several months of the pandemic (from December, 2019 until April, 2020). All responding faculty members were established in their online teaching even though, for many faculty members at many universities across the United States transitioning to online courses was new and sudden. There were 16 participants from each institution (32 in total). All faculty participants were fully online faculty members and served as a chair/mentor for at least one online doctoral student in the dissertation/doctoral study phase of an online doctoral program; this was verified through background questions to ensure that the participants met the criteria for participation.

The faculty participants in both institutions were a mix of both full-time and part-time faculty members. Participation in the online surveys was completely voluntary, and no incentives were provided for completion.

\section{Instrument}

The survey was a combination of Likert-scale items (very, somewhat, slightly, not at all) where participants were asked to indicate their level of agreement with the given statement. The survey included open-ended items where participants were asked follow-up questions and to give more details regarding their own experiences. Statements included perceptions of thoughts on their ability to support student progress, motivate student progress, establish positive working relationships with students, and mentor students. The survey included 20 items.

Initial items were included to ensure that participants met the criteria to participate:

1. What is your role at the university? (student, faculty)

2. If faculty, do you work with doctoral (EdD, $\mathrm{PhD}$, or EdS) students in a fully online program?

3. If yes, do you work with students during the doctoral study/dissertation/capstone phase?

4. Do you serve as the chair for online students during the doctoral study/dissertation/capstone phase? 
5. If no, thank you for your willingness to participate, but this study focuses on faculty who serve as chairs for online doctoral students during the doctoral study/dissertation/capstone phase of the program.

The survey was expected to take 10-15 minutes to complete. The full survey can be found in the Appendix. The findings for each research question are presented in the next section.

\section{Findings}

Based on the responses, most faculty participants seemed to be highly confident in their skills to support online doctoral students with the dissertation/doctoral study. Many faculty participants mentioned their numerous years of experience (most reported 10-30 years) serving as a chair for online doctoral students. Similarly, many participants stated that they had served as the chair for numerous students who had successfully graduated (some reported as many as 100+ students who graduated). Altogether, most of the faculty participants seemed highly skilled in their work as a virtual mentor for online doctoral students.

The results of each research question ( 1 and 2) are presented below in Table 1 . Note that although the choices "somewhat" and "not at all" were offered for Likert-scale items, these were not selected for any item.

Table 1. Survey Results for Faculty Likert-Scale Items

\begin{tabular}{|c|c|c|c|}
\hline Survey Item & Institution A (n) & Institution B (n) & Total (n) \\
\hline \multicolumn{4}{|c|}{ Confidence in their ability to provide support to students } \\
\hline Very & 16 & 8 & 24 \\
\hline Somewhat & o & 8 & 8 \\
\hline \multicolumn{4}{|c|}{ Ability to motivate students in their progression } \\
\hline Very & 5 & 6 & 11 \\
\hline Somewhat & 11 & 10 & 21 \\
\hline \multicolumn{4}{|c|}{ Positive working relationship with students } \\
\hline Very & 15 & 15 & 30 \\
\hline Somewhat & 1 & 1 & 2 \\
\hline \multicolumn{4}{|c|}{ Skillset level to mentor students } \\
\hline Very & 16 & 9 & 25 \\
\hline Somewhat & o & 7 & 7 \\
\hline \multicolumn{4}{|c|}{ Outreach level for students who stop making progress } \\
\hline Very & 15 & 9 & 24 \\
\hline Somewhat & 1 & 7 & 8 \\
\hline \multicolumn{4}{|c|}{ Accommodating students to motivate them } \\
\hline Very & 12 & 12 & 24 \\
\hline Somewhat & 4 & 4 & 8 \\
\hline \multicolumn{4}{|c|}{ Availability of chair to support progress } \\
\hline Very & 13 & 16 & 29 \\
\hline Somewhat & 3 & o & 3 \\
\hline
\end{tabular}

Note. $n=32$ ( $n=16$ for each institution) 
Research Question 1 asked, how do virtual faculty members support motivation (i.e., autonomy, competence, and relationships) of online doctoral students? When asked how faculty members support their student's motivation to make progress, respondents stated that they developed a relationship with the student through personal connections, which may develop trust in the student's perception of the faculty member to support their progress to completion. When asked "To what extent do you feel you have the ability to..." for the following Likert-scale items, most mentioned they felt very $(n=30)$ or somewhat $(n=2)$ confident that they can develop a positive working relationship with their students. When asked to what extent they make themselves available to students, most said they believed they do so to a very $(n=29)$ or somewhat $(n=3)$ great extent.

Most stated they will customize the strategies that each student needs to feel supported. Faculty members reported that some students may need weekly video chats while others need encouraging text messages or emails. However, these high-functioning faculty members have enough autonomy and feelings of competency in their own skills to offer what is needed to support each student. In this way, faculty members declared they use an individualized approach to match the various academic needs and life situations of their students. When asked if they accommodated students and motivated them, faculty members responded that they do this to a very $(n=24)$ or somewhat $(n=8)$ great extent. Faculty members also indicated that they acknowledged students' feelings and provided positive reinforcement to motivate students forward in their research.

There was some differentiation in results between institutions A and B in the areas of having the skillset required to mentor students (Institution A: very $=16$; Institution B: very $=9$, somewhat $=7$ ), and confidence in their ability to provide support to students (Institution A: very = 16; Institution B: very = 8, somewhat $=8$ ).

Research Question 2 asked, how do virtual faculty members act as mentors to online doctoral students?

Many faculty members stated that they encourage their students to break down the dissertation process into small, observable, manageable goals and gave advice to students on how to manage their feelings and emotions toward the research process. When appropriate, faculty members also provided students additional resources and encouraged students to receive additional feedback from their dissertation committee members.

The two faculty respondents who rated somewhat on motivating students' progress stated they could do more to ensure students were moving forward. All others mentioned various things they do to motivate students' progress, such as establishing a positive working relationship with students by connecting with them (e.g., through humor, telling students stories about their own experiences as a student, and being encouraging). Other strategies, such as taking an interest in the students' lives (i.e., showing students that faculty members care) and through regular communication were also mentioned by faculty members.

Working to develop the students' competency is also crucial to promoting motivation to progress. Providing timely feedback was mentioned by most faculty members as a factor in how they support students' progress. This feedback approach also promotes a positive working relationship between the students and faculty members. Additionally, having high expectations (i.e., expecting tasks done well and timely) and providing resources as needed also helps the students develop their own competency.

When asked "what might help you expand your skills as a mentor?" many faculty members said that additional training on this topic as well as other specific areas (e.g., quantitative skills) would be helpful. Others mentioned a desire to be a part of an online forum or space where colleagues could share tips about how to support doctoral students. Several faculty members cited that being shadowed by a senior colleague who could act as a mentor for them (not a supervisor) would also be helpful; the faculty member then could get feedback on how they are supporting their students without feeling like they were being evaluated. 


\section{Discussion}

\section{Developing a Positive Working Relationship}

As students are developing their own competency during the dissertation/doctoral study phase, they must rely on the competency of the faculty member to help them work through the research study. As the students make progress and achieve key milestones (e.g., passing the proposal), they feel more and more confident in the faculty chair and begin to develop their own feelings of competency about their research skills. As the relationship develops and the students continue to make progress in the study, the students' motivation continues to grow. With pain points (e.g., third member rejects the document), the chair must continue to nurture the relationship by positively encouraging the student. This positive encouragement not only nurtures the relationship between the chair and student but also further develops the students' perceptions of their own competency in research skills (Rademaker et al., 2016). Many faculty members stated that they provided student support by sharing their own research experiences and allowing students to share their frustrations throughout the process. This develops a positive working relationship between the chair and student. Many faculty members also indicated that they help provide reasonable expectations and smaller, more manageable tasks for the student to promote the students' competency. This further influences the positive working relationship between the chair and student. These findings directly illustrate the constructs of relationship and competency found in the Deci and Ryan's Self-Determination Theory (1985).

\section{Developing the Student's Competency}

Many of these faculty members mentioned that they feel and demonstrate their autonomy by using the ability to change their strategies to provide support based on the student's needs. Many faculty respondents stated a desire to learn more and even be shadowed by a mentor faculty member to get feedback on their skills. This reflective attitude demonstrates the high-quality respondents as well as a desire to successfully support students in this endeavor. These findings illustrate the framework's construct of faculty autonomy in the process of developing student competency.

\section{Conclusion}

High attrition rates for doctoral programs across all academic disciplines continue to be a concern (Litalien \& Guay, 2015), particularly for online learning modalities (Deshpande, 2017). Students may decide to discontinue their doctoral studies because of their dissertation chair's capabilities and the challenges that they experience in conducting their research (Andrews, 2016). Dissertation chairs have an important role in guiding their mentees in their dissertation studies. However, Mirick et al. (2020) stated that "little is known about the process of becoming a chair, chairs' understanding of this role and their relationships with students, the scope of the role, and the ways these beliefs may be consistent or different from chair to chair" (p. 155).

\section{For Further Research}

To better understand how faculty members can support their online learners in the dissertation process, further research can be conducted on student perceptions of how mentor faculty members support their motivation through specific guidance (e.g., feedback, tasks, communication, etc.). For example, do students feel unmotivated when they receive faculty feedback on their need to revise their original study and research ideas? Particularly, researchers can examine student performance and feelings of motivation during the dissertation stage. Rademaker et al. (2016) shared that dissertation students often have a difficult time realizing and understanding that the dissertation is a process. Moreover, students completing their doctoral program online are more likely to feel isolated; however, student motivation is a critical determinant particularly during this stage of their program for them stay connected (relatedness) and progress (Sverdlik \& 
Hall, 2020). Yet, dissertation chairs may experience difficulties in guiding their students and preparing them for the transition from student to independent scholar (Pifer \& Baker, 2016).

Mirick et al. (2020) postulated that faculty members and students often have different perspectives on why students decide to discontinue their doctoral studies. As such, additional research needs to be conducted on better understanding how dissertation chairs can support students throughout their dissertation and developing an understanding of why students fail to complete their degrees. Further, because participants at each of the institutions we studied were required to complete slightly different faculty training, researchers could also investigate how these types of trainings possibly influence mentorship approaches. Additionally, researchers could also investigate the influence of programs offered at institutions, such as faculty mentorship programs in which novice and veteran chairs are partnered for professional development.

Other research using self-determination theory as a framework may include focusing more on autonomy and how a loss of a feeling of autonomy (from the student's perspective) may negatively influence feelings of motivation. Such a study will further the research already conducted to balance both autonomy and ensure the feasibility and rigor needed for the capstone deliverable. Additionally, research involving autonomy and its influence on faculty and how their motivation to support their students while adhering to university guidelines, policies, and other committee members' feedback influence their motivation to support students is needed. Such an investigation can also include examining if such loss of faculty autonomy also influences their motivation to stay in the profession or position.

Other research might focus on training courses specifically focused on mentoring faculty. Programs might include partnering novice and veteran chairs to share thoughts and ideas on how best to support students. Both new and long-standing faculty members may ultimately benefit from such a partnership, which may influence feelings of motivation to remain in the field and position. Ultimately, faculty members have shown that the successful mentoring of doctoral students requires a variety of strategies that involve building positive working relationships with and developing students' competency to complete their programs. Supporting online doctoral students' motivation to progress and, ultimately, graduate is key to serving students and higher education at large to develop future scholars for positive social change. 


\section{References}

Andrews, K. (2016). Correlation between mentors and learners perceptions of mentors behaviors in completing online doctoral dissertations. Journal of Higher Education Theory and Practice, 16(2), 71-80.

Bohan, C. H., \& Perrotta, K. A. (2020). A reflective study of online faculty teaching experiences in higher education. Educational Policy Studies Faculty Publications 31.

DeCharms, R. C. (1968). Personal causation: The internal affective determinants of behavior. Academic Press.

Deci, E. L., \& Ryan, R. M. (1985). Intrinsic motivation and self-determination in human behavior. Plenum. https://doi.org/10.1007/978-1-4899-2271-7

Deshpande, A. (2017). Faculty best practices to support students in the "virtual doctoral land." Higher Education for the Future, 4(1), 12-30. https://doi.org/10.1177/2347631116681211

Flavell, J. H. (1999). Development of children's knowledge about the mental world. International Journal of Behavioral Development, 24(1), 15-23. https://doi.org/10.1080/016502500383421

Kayapinar, U. (2016). A study on reflection in in-service teacher development: Introducing reflective practitioner development model. Educational Sciences: Theory \& Practice, 16(5), 16711691. https://doi.org/10.12738/estp.2016.5.0077

Kumar, S. \& Johnson, M. (2017). Mentoring doctoral students online: mentor strategies and challenges. Mentoring \& Tutoring: Partnership in Learning, 25(2), 202-222, https://doi.org/10.1080/13611267.2017.1326693

Kumar, S., \& Coe, C. (2017). Mentoring and student support in online doctoral programs. American Journal of Distance Education, 31(2), 128-142. https://doi.org/10.1080/08923647.2017.1300464

Litalien, D., \& Guay, F. (2015). Dropout intentions in PhD studies: A comprehensive model based on interpersonal relationships and motivational resources. Contemporary Educational Psychology, 41, 218-231. https://doi.org/10.1016/j.cedpsych.2015.03.004

Mahsood, N., Ahaan, A., Atzai, N., \& Aziz, S. (2018). Teacher's perceptions of faculty development workshop. Kaohsiung Journal of Medical Sciences, 11, 129-132.

Mirick, R. G., Davis, A., \& Wladkowski, S. P. (2020). Social work dissertation committee chairs' perceptions of their roles. Journal of Social Work Education, 56(1), 155-169. https://doi.org/10.1080/10437797.2019.1642273

Pifer, M. J., \& Baker, V. L. (2016). Stage-based challenges and strategies for support in doctoral education: A practical guide for students, faculty members, and program administrators. International Journal of Doctoral Studies, 11, 15-34. http://ijds.org/Volume11/IJDSv11p015-034Pifer2155.pdf

Rademaker, L. L., O’Connor Duffy, J., Wetzler, E., \& Zaikina-Montgomery, H. (2016). Chair perceptions of trust between mentor and mentee in online doctoral dissertation mentoring. Online Learning, 2O(1), 57-69. https://doi.org/10.24059/olj.v20i1.605

Ryan, R. M., \& Deci, E. L. (2000). Self-determination theory and the facilitation of intrinsic motivation, social development, and well-being. American Psychologist, 55(1), 68-78. https://doi.org/10.1037//ooo3066x.55.1.68

Saiyad, S., Virk, A., Mahajan, R., \& Singh, T. (2020). Online teaching in medical training: Establishing good online teaching practices from cumulative experience. International Journal of Applied \& Basic Medical Research, 1O(3), 149-155. https://doi.org/10.4103/ijabmr.IJABMR_358_20 
Steinert, Y., Mann, K., Anderson, B., Barnett, B. M., Centeno, A., Naismith, L., Prideaux, D., Spencer, J., Tullo, E., Viggiano, T., Ward, H., \& Dolmans, D. (2016). A systematic review of faculty development initiatives designed to enhance teaching effectiveness: A 10-year update: BEME Guide No. 40. Medical Teacher, 38(8), 769-786.

Sverdlik, A., \& Hall, N. C. (2020). Not just a phase: Exploring the role of program stage on well-being and motivation in doctoral students. Journal of Adult and Continuing Education, 26(1), 97-124. https://doi.org/10.1177/1477971419842887

Taylor, D., Grant, J., Hossam, H., Grant, L., Marei, H., \& Venkatramana, M. (2020). Transformation to learning from a distance. MedEdPublish, 9(1), 76. https://doi.org/10.15694/mep.2020.000076.1

Templeton, R. (2016). Doctorate motivation: An (auto)ethnography. Australian University Review, 58(1), $39-44$.

Thunborg, C., Bron, A., \& Edström, E. (2013). Motives, commitment and student identity in higher education-experiences of non-traditional students in Sweden. Studies in the Education of Adults, 45(2), 177-193. https://doi.org/10.1080/02660830.2013.11661650

Yin, R. K. (2003). Case study research: Design and methods. Sage.

Yin, R. K. (2014). Case study research. Sage. 


\section{Appendix}

Please select the most appropriate answer for how you feel currently.

1. To what extent do you feel you have the ability (i.e., skills/knowledge) to support students' progress on their dissertation/doctoral study? (very, somewhat, slightly, not at all)

2. Why or why not? (open-ended comment box)

3. To what extent do you feel you motivate your students' progress on their dissertation/doctoral study? (very, somewhat, slightly, not at all)

4. How so? (open-ended comment box)

5. To what extent do you feel you work to establish a positive working relationship with your students? (very, somewhat, slightly, not at all)

6. In what ways do you work to establish a working relationship with your student? (open-ended comment box)

7. To what extent do you feel you have the skills to mentor online doctoral students? (very, somewhat, slightly, not at all)

8. What training (if any) have you received focused on mentoring online dissertation students? Please describe. (open-ended comment box)

9. What might be helpful for you to expand your skills as an online mentor? (e.g., additional training, a faculty mentor for other faculty, etc.) (open-ended comment box)

10. When a student in which you are chairing seems to slow down or stop making progress, to what extent do you purposefully reach out to the student to check on their motivation? (very, somewhat, slightly, not at all)

11. What else do you do to support a student whose motivation seems hindered? Please describe. (openended comment box)

12. How do you support your students when they seem to be frustrated? (open-ended comment box)

13. To what extent are you flexible in your support of each student to accommodate their needs to stay motivated and progress? (very, somewhat, slightly, not at all)

14. How so? (open-ended comment box)

15. To what extent do you make yourself available to your students in order to support their progress on their doctoral study? (very, somewhat, slightly, not at all)

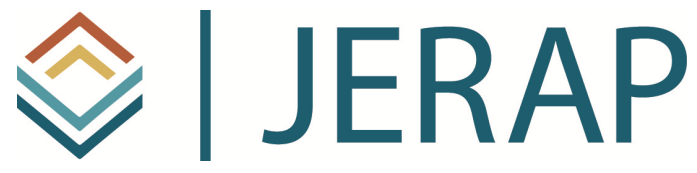

The Journal of Educational Research and Practice is a peerreviewed journal that provides a forum for studies and dialogue about developments and change in the field of education and learning. The journal includes research and related content that examine current relevant educational issues and processes. The aim is to provide readers with knowledge and with strategies to use that knowledge in educational or learning environments. JERAP focuses on education at all levels and in any setting, and includes peer-reviewed research reports, commentaries, book reviews, interviews of prominent individuals, and reports about educational practice. The journal is sponsored by The Richard W. Riley College of Education and Leadership at Walden University, and publication in JERAP is always free to authors and readers. 